\title{
Area-restricted searching by manta rays and their response to spatial scale in lagoon habitats
}

\author{
Yannis P. Papastamatiou ${ }^{1, *}$, Paul A. DeSalles ${ }^{2}$, Douglas J. McCauley ${ }^{2,3}$ \\ ${ }^{1}$ Florida Museum of Natural History, University of Florida, Museum Rd and Newell Drive, Gainesville, Florida 32605, USA \\ ${ }^{2}$ Hopkins Marine Station, Stanford University, Pacific Grove, California 93950, USA \\ ${ }^{3}$ Department of Environmental Science, Policy and Management, University of California Berkeley, \\ Berkeley, California 94720, USA
}

\begin{abstract}
Animals may use a variety of search patterns to locate resources when the exact locations of those resources are unknown. Theoretical and empirical evidence suggests that the optimal type of random walk will vary based on the distribution of resources such as prey. Once resources are located, the animal may utilize a movement strategy that allows it to remain within a small area and maximize resource acquisition (area-restricted searching, ARS). Detecting the location of ARS zones is important, as it identifies profitable habitat to the animal, although such analysis is rarely conducted with fishes. We utilized correlated random walk (CRW), fractal, and first passage time (FPT) analysis to quantify the response of planktivorous manta rays Manta alfredi to spatial scale and identify locations of ARS within lagoons at Palmyra Atoll. Mantas used CRWs at small spatial scales to move between prey patches, but not at larger scales as they performed home-ranging behavior. One domain was located with straighter movements at scales $<330 \mathrm{~m}$, and more tortuous movements at scales $>330 \mathrm{~m}$. ARS was located adjacent to ledges with high abundance of plankton, or within channels. Fractal and FPT analyses suggest that mantas used patches that were 5 to $49 \%$ of the scale of their activity space over short time periods (days). Quantitative analytical tools help explain observed patterns of movements and demonstrate the importance of lagoon habitats to these macro-planktivores.
\end{abstract}

KEY WORDS: Correlated random walks - First passage time - Fractal analysis - Mantas · Movement · Palmyra

Resale or republication not permitted without written consent of the publisher

\section{INTRODUCTION}

Mobile animals develop search patterns and select habitats which improve their ability to find prey, shelter from predators, and potential mates. The mechanisms and behaviors that shape these movement and habitat selection decisions can vary considerably over multiple temporal and spatial scales. Teasing apart the factors that regulate movements of large marine animals is particularly problematic, as the animals reside within a concealing medium where their specific behaviors cannot be readily observed. In some situations, emerging technologies can be used to directly infer specific behaviors (e.g. feeding, Bestley et al. 2010), but in the majority of cases we are left with indirectly inferring as much as possible about their behavioral ecology from movement path structure.

Animals typically utilize 2 general types of movements: directed walks when they head towards a known goal or location (Nams 2006, Papastamatiou et al. 2011) and random walks when the exact locations of resources are unknown and subjects travel across space without a clear spatial goal (e.g. Bartumeus et al. 2005). Most studies compare animal movements to the predictions of a correlated random walk (CRW), where movements are random, but there exists some correlation between sequential movement steps which gives rise to an emergent directional bias in travel over short time periods (e.g. 
Kareiva \& Shigesada 1983). Computer simulations predict that straighter CRWs will have higher encounter success with patches than more tortuous CRWs, although the difference between the various walks is reduced when the abundance of resources is high (Zollner \& Lima 1999). In recent years there has also been increasing interest in whether animals move using Lévy flights, another class of random walk whereby the length of movement steps conform to a probability distribution with a heavy-tailed power law (Viswanathan et al. 1999, Humphries et al. 2010). Lévy flights thus typically contain many short movements punctuated by occasional long-range movements, repeated at all spatial scales, which reduce the chance of an animal re-searching the same area (Viswanathan et al. 1999). However, for Lévy flights to be detected, movements should be measured over long spatial and temporal scales (Bartumeus et al. 2005).

Animals are likely to switch between modes of movement as they move within and between patches of resources. Once prey is encountered, the animal may switch to a movement strategy that allows it to remain in a small area, as the probability of encountering additional prey items in the immediate vicinity is high (termed area-restricted searching, ARS; Benhamou 1992). Heterogeneity in movements can cause animals to respond differently to their environment at the various spatial scales (e.g. Fritz et al. 2003, Nams 2005). These transitions in movement structure at various spatial scales are known as domains, and for a full understanding of how an animal ecologically responds to its landscape, domains should be quantified (e.g. Fritz et al. 2003). Quantifying the scale and/or the location of domains and patch use, and relating these to environmental conditions or prey abundance, can greatly improve our understanding of the factors which drive animal movements and cause them to conform or depart from model predictions (e.g. Fauchald \& Tveraa 2003, Fritz et al. 2003).

Mobile filter-feeding marine planktivores are unique in that movements of these animals are intimately coupled to their foraging; they must move in order to filter prey from their environment and thus their patterns of movement very closely reflect the ecology of their foraging (Paig-Tran et al. 2011). Furthermore, with the capacity to directly measure the abundance of the planktonic prey of filter feeders, we can empirically examine whether postulated differences in forage do indeed create the patterns of movement we observe (e.g. Sims \& Quayle 1998, Sims et al. 2006). Under these conditions, it becomes intuitive to use quantitative analytical tools to determine search patterns in large filter feeders, and to predict which factors may drive observed patterns of movements.

Here we used 3 complementary tools: CRW, fractal, and first passage time (FPT) analysis to quantify search patterns and ARS in a macro-planktivore, the manta ray Manta alfredi, at Palmyra Atoll, Pacific Ocean. Fractal analysis quantifies the geometry of a movement path and uses it to identify spatial domains and spatial scales of heterogeneous movements, while FPT identifies the scale and location of ARS based on time spent along a movement path (Fauchald \& Tveraa 2003, Doerr \& Doerr 2004). Mantas of many size ranges can be found within the lagoons of Palmyra Atoll, and they actively and habitually use this habitat (P. A. DeSalles et al. unpubl. data). Lagoons are often productive habitats with high plankton biomass, so we predicted that manta rays use straighter CRWs at small spatial scales to move between patches, but demonstrate home-ranging behavior at larger scales. We further predicted that the locations of ARS will be confined to key habitats most likely related to prey (plankton) abundance.

\section{MATERIALS AND METHODS}

\section{Study site}

Palmyra Atoll $\left(5^{\circ} 53^{\prime} \mathrm{N}, 162^{\circ} 05^{\prime} \mathrm{W}\right)$ is located in the Central Pacific Ocean and is part of the Northern Line Islands. The interior of the atoll consists of 2 lagoons; the eastern $\left(1 \mathrm{~km}^{2}\right.$, maximum depth $\left.50 \mathrm{~m}\right)$ and the western lagoon $\left(3 \mathrm{~km}^{2}\right.$, maximum depth 60 m, Fig. 1). The lagoons are separated by a narrow tidal channel (18 m wide), and surrounded by extensive sand flats and coral ledges (Fig. 1). The western lagoon is connected to the outer reefs by a dredged

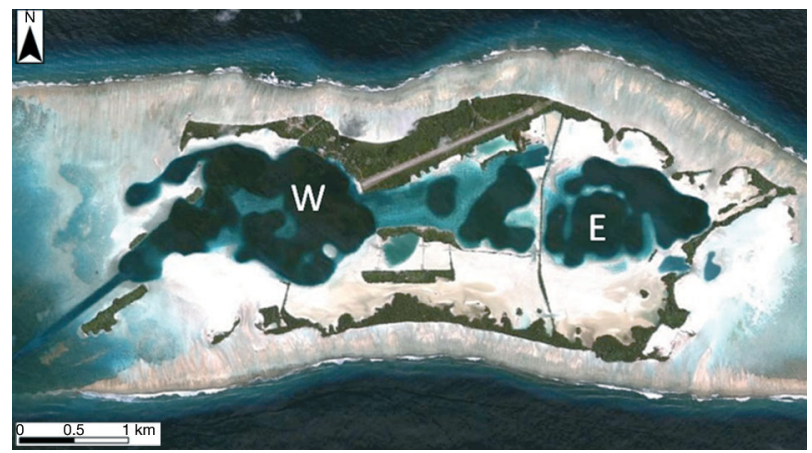

Fig. 1. Aerial image of Palmyra Atoll showing the location of the east (E) and west (W) lagoons 
$1.7 \mathrm{~km}$ channel (8 $\mathrm{m}$ depth). Both lagoons have a mud/sand benthic substratum, and consequently, water visibility is variable but consistently low.

\section{Active tracking}

Manta rays were continuously tracked in both the eastern and western lagoon basins for periods of 5 to $46 \mathrm{~h}$, using externally attached acoustic transmitters (V16, VEMCO), and a VR 100 receiver and hydrophone attached to the side of a $16 \mathrm{ft}(\sim 4.8 \mathrm{~m})$ tracking vessal. Transmitters were attached to small stainless steel darts, and a snorkeler used a pole-spear to tag the manta in the wing. Although the tagging procedure induced a startle response in the mantas, they were often seen feeding within 20 min of tagging. Mantas were tracked using a boat and hydrophone, and GPS positions were manually logged every $5 \mathrm{~min}$. The tracking vessel maintained a distance of at least $10 \mathrm{~m}$ from the animal, but moved to the animal's exact location when obtaining a GPS coordinate. Accurate geo-location estimates were obtained by either visually observing the manta at the water surface, or positioning the tracking vessel directly above the animal when obtaining the location (signal strength was equal in all directions, ground zero). The relatively small size of the lagoons and the surface swimming behavior of the mantas made tracking relatively easy, and location errors were estimated at $\pm 10 \mathrm{~m}$.

\section{Data analysis}

\section{Correlated random walk}

To determine whether manta rays were moving using a CRW, we calculated the $\mathrm{CRW}_{\text {Diff }}$ statistic (Nams \& Bourgeois 2004, Nams 2006):

$$
\mathrm{CRW}_{\text {Diff }}=\frac{1}{k} \sum_{n=1}^{k} \frac{\bar{R}_{n}^{2}-E\left(R_{n}^{2}\right)}{n^{2} I^{-2}-E\left(R_{n}^{2}\right)}
$$

where $\bar{R}_{n}^{2}$ represents the observed mean (net distance) $)^{2}$ for each number of $n$ consecutive moves, $E$ is the expected mean (net distance) ${ }^{2}$ according to the CRW model described by Kareiva \& Shigesada (1983), $l$ is the mean step length, and $k$ is the turning angle concentration. The statistic compares net displacement of an animal over $n$ steps (in our case a step was the change in location over a 5 min period), against the predicted displacement of an animal moving using a CRW. Positive $\mathrm{CRW}_{\text {Diff }}$ values indicate that the animal moved farther than an individual moving randomly, while negative values indicate more constrained movements than a CRW. Confidence intervals were calculated by treating (net distance traveled) ${ }^{2}$ for each segment of $n$ moves as independent samples (Nams \& Bourgeois 2004). We calculated $\mathrm{CRW}_{\text {Diff }}$ for all mantas combined (the statistic treats each individual animal as a replicate) and for each manta individually (where variability represents within-path variation). The results suggest that mantas may utilize a CRW but only at small spatial scales. To investigate this, we re-ran the analysis after discretizing the data by generating a new movement path where every step was equivalent to 30 steps of the original movement path.

\section{Fractal analysis}

The geometry of an animal's movement path can provide insight into its behavior. For example, tortuous movement paths are more indicative of patch use, while straighter movements may suggest transiting between habitats (but see Bestley et al. 2010). The fractal value $(D)$ of a movement path is a measure of tortuosity and can range from 1 for a straight line to 2 for a path that is so tortuous it completely covers a 2-dimensional plane (Nams 1996, 2005, Doerr \& Doerr 2004). We used fractal mean to calculate an overall measure of fractal $D$ for each individual manta. Fractal mean calculates $D$ using the divider method, but includes replication by running dividers both forward and backwards along the movement path (Doerr \& Doerr 2004, Nams 2005). Briefly, dividers are moved along the movement path, and the length of the path is calculated. This procedure is repeated using dividers of increasing size. The larger the size of the dividers, the lower the estimate of path length, as movement sections will be lost between divider transitions. A log-log plot of divider size versus path length is generated, with a slope of $1-D$. The line can be described by $L(G)=$ $k G^{1-D}$ where $L(G)$ is path length, $k$ is a constant, and $G$ is divider size (Nams 1996, Doerr \& Doerr 2004). More tortuous paths will have more turns, and the log-log plot will have a steeper slope, and hence produce a higher fractal value. For 2 mantas tracked in the eastern lagoon (Manta 1 and 2, Table 1), we determined the effect of plankton biomass on movement tortuosity. Movements were separated into sections along specific ledges (based on a $200 \mathrm{~m}$ buffer from the ledge), and $D$ was calculated for each section (only continuous movements were utilized, and the same range of dividers, 10 to $200 \mathrm{~m}$, was used for 
Table 1. Manta alfredi. Movement statistics and track duration for manta rays tracked in the Palmyra lagoons, showing the mean Fractal value $(D)$, difference in net distance moved from the predictions of a correlated random walk $\left(\mathrm{CRW}_{\text {Diff }}\right.$, with associated p-values), the spatial scale of area-restricted searching (ARS) determined by first passage time (FPT) analysis, scale of patch use determined from fractal analysis, and scale of activity defined using the longest dimension of the mantas' activity space. N indicates no patch use or ARS was detected. NA indicates that the data were insufficient for processing FPT analyses. Data are represented for each individual tracked and for all mantas pooled. KUD: kernel utilization distribution. Significant values are shown in bold

\begin{tabular}{|c|c|c|c|c|c|c|c|c|c|}
\hline Manta & Track (h) & $D$ & $\mathrm{CRW}_{\text {Diff }}$ & $\mathrm{p}$ & ARS (m) & Patch use (m) & Scale of activity (m) & $95 \%$ KUD $\left(\mathrm{km}^{2}\right)$ & Lagoon \\
\hline 1 & 24 & 1.56 & -0.01 & 0.65 & 160,710 & $72-160$ & 1450 & 0.92 & East \\
\hline 2 & 24 & 1.50 & -0.06 & 0.01 & 450 & $\mathrm{~N}$ & 1330 & 0.89 & East \\
\hline 3 & 46 & 1.46 & -0.04 & $<0.001$ & $\mathrm{~N}$ & $\mathrm{~N}$ & 940 & 0.15 & East \\
\hline 4 & 5 & 1.13 & 0.19 & 0.38 & NA & $\mathrm{N}$ & 3600 & 1.84 & West \\
\hline 5 & 32 & 1.27 & -0.20 & 0.32 & 510 & $275-720$ & 3100 & 0.47 & West \\
\hline 6 & 32 & 1.53 & -0.02 & 0.19 & 710 & $\mathrm{~N}$ & 2600 & 0.34 & West \\
\hline 7 & 32 & 1.43 & 0.02 & 0.44 & 160 & $80-340$ & 2100 & 1.35 & West \\
\hline 8 & 46 & 1.32 & 0.03 & 0.57 & 660 & $100-230$ & 4350 & 1.97 & West \\
\hline 9 & 11 & 1.11 & 0.30 & 0.61 & NA & $190-200$ & 3160 & 1.01 & West \\
\hline 10 & 22 & 1.21 & 0.01 & 0.95 & 510 & $125-625$ & 5760 & 1.61 & West \\
\hline \multicolumn{3}{|c|}{ All mantas } & -0.02 & 0.32 & & & & & \\
\hline
\end{tabular}

each calculation). For all statistical testing, we transformed $D$ into $\log (D-1)$ as recommended by Doerr \& Doerr (2004). To quantify scale-dependent changes in fractal value, we measured VFractal, which determines the fractal value based on turning angles between movement steps (Nams 1996). VFractal also uses a bootstrapping procedure, by randomly selecting turning angles from the movement path, to determine $95 \%$ confidence intervals (CIs) around the means. We used 200 divider sizes between 10 and $2000 \mathrm{~m}$ to calculate all fractal statistics in this section (with exception of ledge-based movements in Mantas 1 and 2, where divider size ranged from 10 to $200 \mathrm{~m}$ ). The number of replications during bootstrapping ranged from 10 at small spatial scales, to 2000 at large scales (where CIs are much larger) with a mean of 1000. There has been some criticism of fractal analysis, largely because early studies assumed that movements were fractal (self-similar) which is rarely the case in animal movement studies, as the fractal value will often vary with scale, particularly if the animal is moving with a CRW (Turchin 1996). However, we were interested in relative values between individuals, and when comparing fractal values we used the same range of divider sizes. We were also specifically interested in the variation in fractal values at different scales (scale-dependent behavior).

To detect patch use, we determined the correlation in tortuosity between adjacent dividers moving along the movement path, for a range of divider sizes (range 10 to $2000 \mathrm{~m}$ ). If the animal uses a patch, and as divider size approximates patch size, the correlation between adjacent dividers should be positive as the divider is moving from outside the patch (low tortuosity) to inside the patch (high tortuosity). As divider size equals patch size, the correlation should be negative, as the divider is going from an area of high tortuosity (the patch is completely enclosed within the divider) to an area of low tortuosity (completely outside the patch, Nams 2005). Therefore, a positive peak in correlation followed by a negative trough is indicative of the scale of heterogeneous movements. If there is no patch use, then the correlation should be 0 regardless of whether the animal is moving using a random or directed walk (Nams 2005). We used Fractal ver. 5.0 for all fractal and CRW analysis (V. Nams, Nova Scotia Agricultural College, Canada). As a metric of activity space, we calculated the 95\% kernel utilization distribution (KUD) with an ad hoc smoothing parameter, using the Animal Movement extension in ArcView 3.3. Any section of the KUD going over land was manually removed.

\section{Area-restricted searching}

To detect periods of ARS, we used First Passage Time (FPT) analysis. The FPT is a measure of how much time it takes an animal to cross a circle of a given radius. The rate of change in FPT will vary based on how tortuous the animal's movements are, and how much time the animal spends within that circle. It has been shown that the variance in FPT will peak at the spatial scale of ARS (Fauchald \& Tveraa 2003). In some sense, FPT is a time analogue to the fractal analysis used to identify patch use described 
in the previous section. While fractal analysis identifies patch use based on the geometric shape of the movement path, FPT identifies ARS based on the time spent searching. Variance is log transformed so that it becomes independent of mean FPT. As such, FPT analysis can indicate the spatial scale of ARS and when it occurs during a given track (Fauchald \& Tveraa 2003). We determined FPT for each individual manta using the Ethographer package (http:// sites.google.com/site/ethographer/home) in Igor Pro ver. 6.21. We set the smallest radius at $10 \mathrm{~m}$, and maximum radius as the largest dimension of the mantas' activity space. FPT was calculated in $50 \mathrm{~m}$ increments. We used a paired $t$-test to compare the size of ARS determined by FPT with patch use by fractal analysis.

\section{Plankton tows}

We sampled plankton biomass across 10 evenly spaced sites in Palmyra's east lagoon. We established $240 \mathrm{~m}$ transect lines along the ledge perimeter of the lagoon at each site and collected plankton using $350 \mu \mathrm{m}$ mesh nets. Each ledge site was sampled between 6 and 9 times. Dry biomass of plankton standardized by water volume from each site was compared. Designation of plankton collection sites as 'high' or 'low' was based on plankton biomass collected and the presence of biotic and abiotic factors that influence plankton availability and growth (McCauley et al. 2012). Briefly, Palmyra's terrestrial forest fauna consists of native Pisonia grandis and Tournefortia argentea trees, and the human-facili- tated coconut palm Cocos nucifera. The forest has fractured into patches of native and introduced trees. Seabirds show much higher selection for native trees, and subsequently nutrient run-off and plankton biomass in adjacent waters are higher in these locations (Young et al. 2010, McCauley et al. 2012). Ledge classification was also based on their proximity to native or introduced forest trees.

\section{RESULTS}

We actively tracked 10 manta rays for periods of 5 to $46 \mathrm{~h}$ (mean $\pm 1 \mathrm{SD}$ here and throughout manuscript, $27 \pm 13 \mathrm{~h}$, Table 1 ). We visually estimated animals to have wing spans ranging from approximately 1.2 to $2.6 \mathrm{~m}$. Three individuals were tracked in the smaller eastern lagoon, while 7 were tracked in the western lagoon. During the tracking period, manta rays had $95 \%$ KUDs of 0.15 to $1.97 \mathrm{~km}^{2}$, and maximum dimensions of 940 to $5760 \mathrm{~m}$. These results represent data for continuous tracking. However, mantas were often relocated in the respective lagoons over periods of weeks (P. A. DeSalles unpubl.).

\section{Correlated random walk}

When analyzed collectively, manta rays in the lagoons of Palmyra utilized movements similar to a CRW $\left(\mathrm{CRW}_{\text {Diff }}=-0.024, \mathrm{p}=0.32, \mathrm{df}=7\right.$, Fig. 2A). When analyzed individually, all but 2 individuals also moved similar to a CRW (Table 1). However, the $\mathrm{CRW}_{\text {Diff }}$ test may not be able to differentiate a move-

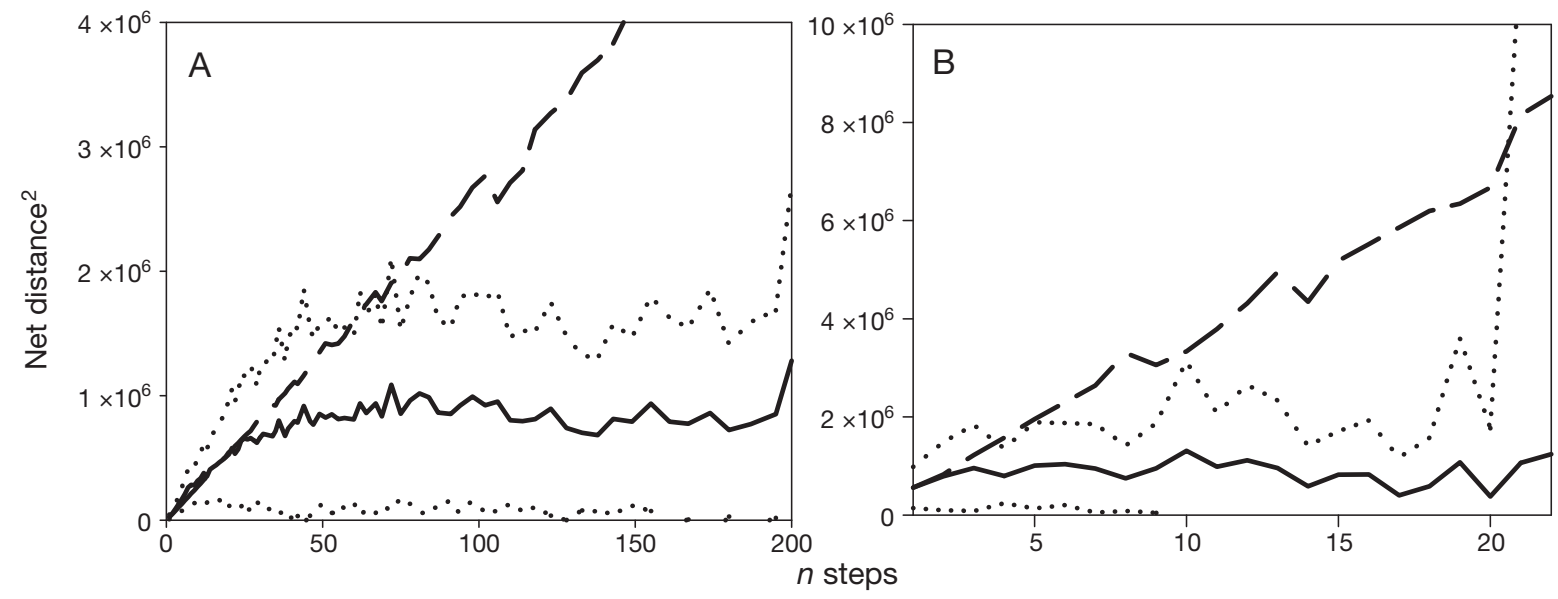

Fig. 2. Manta alfredi. Observed net distance ${ }^{2}$ moved over $n$ movement steps (solid black line is mean, dotted lines are $95 \%$ CI), as well as predicted values if the mantas were moving using a correlated random walk (CRW, dashed line), for all mantas combined $(n=8)$. Movements in B have been discretized so that 1 step $=30$ steps in A. At smaller spatial scales, mantas used movements similar to a CRW ( $\left.A, C_{\text {Diff }}=-0.024, p=0.32\right)$ but not at larger scales $\left(B, C_{\text {Diff }}=-0.15, p=0.008\right)$ 
ment path that is homogeneous (i.e. a CRW) from one which is heterogenous with heavy patch use (Nams 2005). In addition, while the change in displacement matched the predictions of a CRW at small spatial scales (30 to 50 movement steps), at larger spatial scales movements appeared much more constrained than a CRW (Fig. 2A). Based on these facts and because patch use was identified (see below), we reanalyzed the movement by discretizing the path. When the discretized movement paths were analyzed, mantas did not appear to utilize a CRW $\left(\mathrm{CRW}_{\text {Diff }}=-0.15, \mathrm{p}=0.008, \mathrm{df}=7\right.$, Fig. $\left.2 \mathrm{~B}\right)$. Therefore, mantas may use a CRW at smaller but not larger spatial scales.

\section{Fractal analysis}

The change in fractal $D$ with spatial scale suggested that manta rays utilized a domain, with an abrupt change in the pattern at spatial scales of $330 \mathrm{~m}$ (Fig. 3A). There was a gradual increase in fractal $D$ from spatial scales of 10 to $330 \mathrm{~m}$, but scale invariant movements at scales $>330 \mathrm{~m}$ (Fig. 3A). Based on this domain, we calculated 2 measures of $D$, with $D_{1}$ at scales of 10 to $330 \mathrm{~m}$, and $D_{2}$ at scales of 330 to 1000 m (see Nams \& Bourgeois 2004). Movements at the smaller scales were less tortuous $\left(D_{1}\right.$ : $1.16 \pm 0.06)$ than at larger scales $\left(D_{2}: 2.03 \pm 0.97\right.$, paired $t$-test, $t=-7.29, \mathrm{p}<0.0001, \mathrm{df}=7$ ). The peak and trough in the correlation in tortuosity between path segments show that mantas did perform heterogeneous movements at times, with overall patch use at scales of 300 to $500 \mathrm{~m}$ (Fig. 3B).
When movements were examined individually, there were 2 general patterns. Five individuals showed homogeneous movements at all spatial scales (no obvious transitions), while the remaining individuals showed homogeneous movements at smaller spatial scales and more scale invariant movements at scales $>100 \mathrm{~m}$. Manta 1 showed 2 domains, with scale-dependent movements up to $75 \mathrm{~m}$, scale invariant movements from 75 to $150 \mathrm{~m}$ (no increase in fractal $D$ ), and homogeneous movements again at scales $>150 \mathrm{~m}$ (Fig. 4A). There was some evidence of patch use for this individual at spatial scales of 73 to $160 \mathrm{~m}$ (Fig. 4B). Collectively, this suite of behaviors suggests that this individual made random movements within patches and at larger scales, but sometimes used a directed walk to move between patches (as indicated by the scale invariant movements, Doerr \& Doerr 2004, Papastamatiou et al. 2009). Combined, fractal analysis suggested that manta rays at Palmyra Atoll used patches that were 5 to $23 \%(4 \pm 7 \%)$ of the scale of their activity space.

Mantas tracked in the eastern lagoon performed more tortuous movements while moving along ledges that were field identified as regions with elevated plankton abundance (high ledges, plankton biomass $0.14 \pm 0.04 \mathrm{~g} \mathrm{~m}^{-3}, D=1.35 \pm 0.03$; low ledges, plankton biomass: $0.04 \pm 0.01 \mathrm{~g} \mathrm{~m}^{-3}, D=1.26 \pm 0.02$; for plankton, $t=4.02, \mathrm{df}=7, \mathrm{p}<0.01$; for fractal $D, t=$ $2.31, \mathrm{p}=0.028$ ). For Mantas 1 and 2, movement tortuosity appeared to increase with increasing plankton biomass, until a plateau was reached at approximately $0.1 \mathrm{~g} \mathrm{~m}^{-3}$ (Fig. 5). A logarithmic curve provided a good fit to the biomass data for Manta $2(F=$ 14.08, $\mathrm{df}=4, \mathrm{p}=0.03, \mathrm{r}^{2}=0.82$ ), while a single outlier
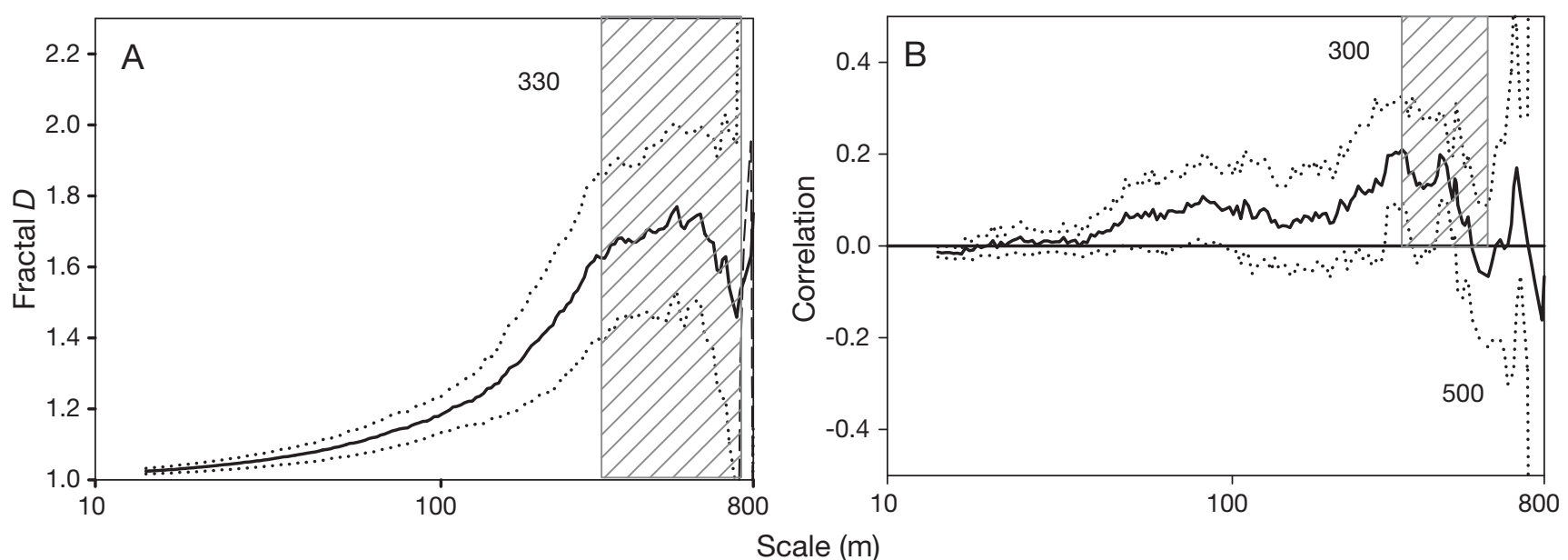

Fig. 3. Manta alfredi. Fractal analysis of manta movements within the Palmyra lagoons $(\mathrm{n}=8)$. (A) Changes in fractal $D$, and $(\mathrm{B})$ the correlation in tortuosity between divider segments. The location of domains (A) and patch use (B) are given in the shaded areas. Mantas tended to use patches of 300 to $500 \mathrm{~m}$ in scale. The $\mathrm{x}$-axis is presented on a log scale. Lines are means and $95 \%$ CI 

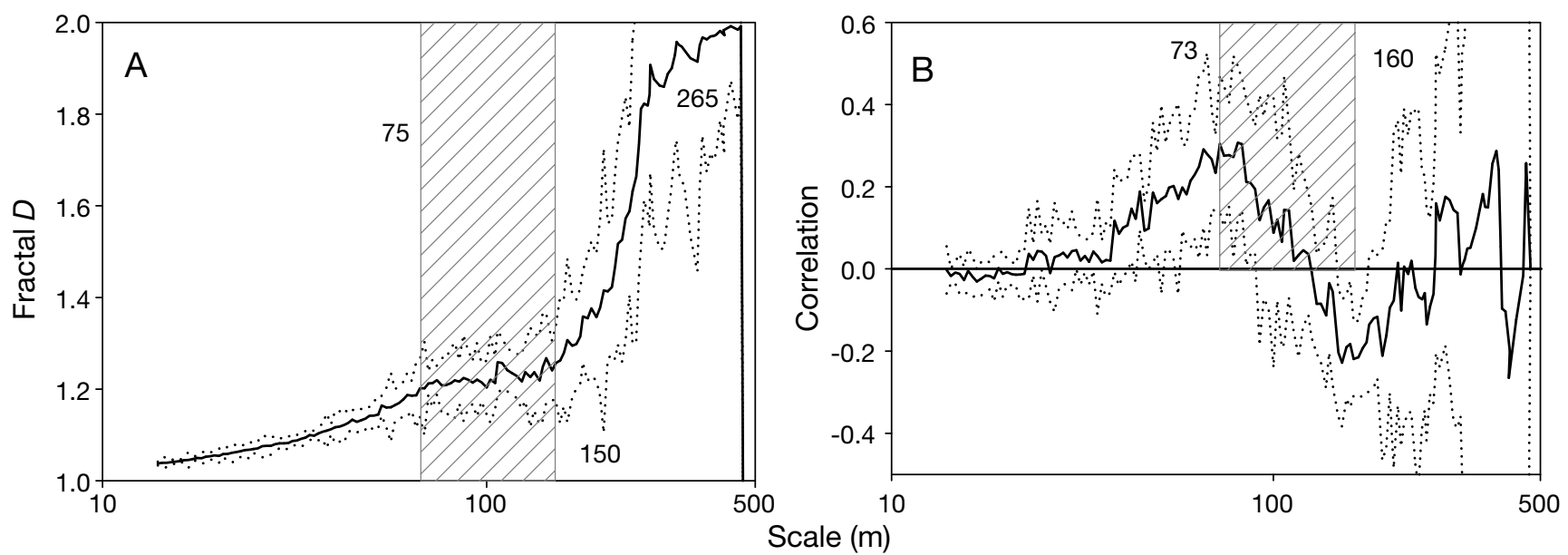

Fig. 4. Manta alfredi. Fractal analysis for Manta 1 (see Table 1). (A) Changes in fractal $D$ and (B) correlation in tortuosity between dividers with spatial scale. Solid lines are means, while dotted lines are $95 \%$ CI. The shaded region shows the location of 2 domains in fractal values (A) and the location of heterogeneous movements (patch use, B). Numbers show the location of domains (A) or patch use (B)

made the relationship non-significant for Manta 1 $(F=0.33, \mathrm{df}=4, \mathrm{p}=0.61)$. However, fractal values of movements for the other ledges were very similar between the 2 individuals (Fig. 5).

\section{Area-restricted searching}

For individuals $(\mathrm{n}=8)$ with enough data for FPT analysis, $88 \%$ of mantas demonstrated some degree of ARS (Table 1). The spatial scale of ARS ranged from 160 to $710 \mathrm{~m}$, representing 8 to $49 \%$ (23 $\pm 15 \%)$ of the scale of the mantas' home range. The locations of ARS were principally detected in regions where their plankton forage was determined to be the highest (specific ledges within the eastern lagoon, see above) or within a channel in the west lagoon (Figs. 6a,b \& 7). For mantas tracked in the east lagoon, 2 individuals (1 and 2) demonstrated ARS to ledges with high plankton biomass. We were not able to detect ARS in Manta 3, but this may have been because the animal's entire movements consisted of ARS (Fig. 7). The majority of this individual's movements were confined to a ledge with the highest biomass of plankton. Of the 5 mantas demonstrating ARS in the west lagoon, 3 did so within the main channel, while the remaining 2 individuals showed preference to a shallow sand bank in the center of the lagoon (Fig. 7). There was good agreement between the analytical techniques, with no significant difference in the scale of ARS measured with FPT and the scale of patch use determined with fractal analysis (paired $t$-test, $t=-0.13, \mathrm{p}=0.90$, Table 1 ).

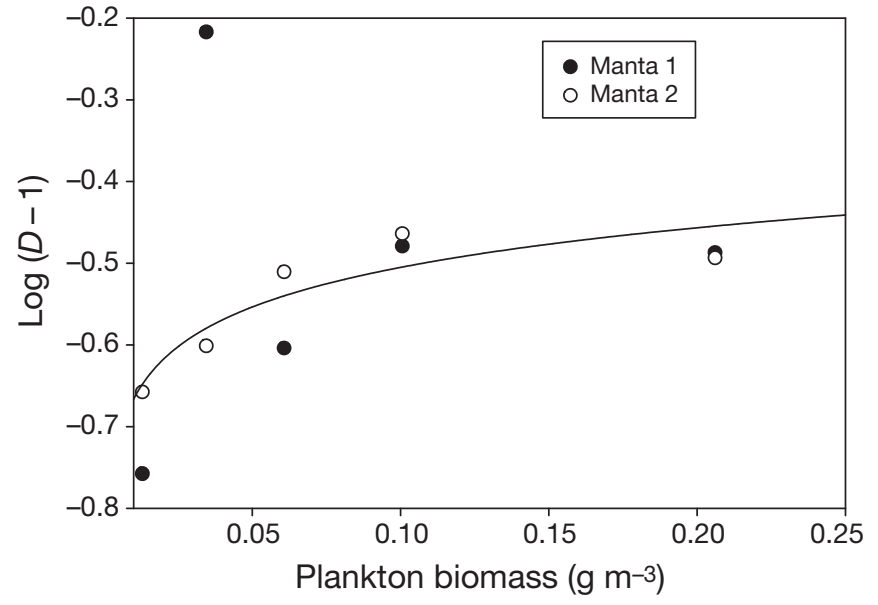

Fig. 5. Manta alfredi. Effects of prey abundance (plankton biomass) on movement tortuosity (fractal value) for 2 manta rays tracked in the east lagoon. A logarithmic curve has been fitted for data from Manta $2\left(F=14.08, \mathrm{p}=0.03, \mathrm{r}^{2}=\right.$ 0.82). Although the regression was non-significant for Manta 1, this was due to 1 outlier point. Note the very similar fractal values between Mantas 1 and 2 for all other movements in plankton patches. Each data point represents movements along a ledge for these 2 individuals

\section{DISCUSSION}

The data obtained from active tracking still provide some of the highest spatial resolution data on fish movements. However, active tracking is a largely neglected tool in the study of animal movements, primarily because of its laborious nature and because movements are only determined over short time peri- 

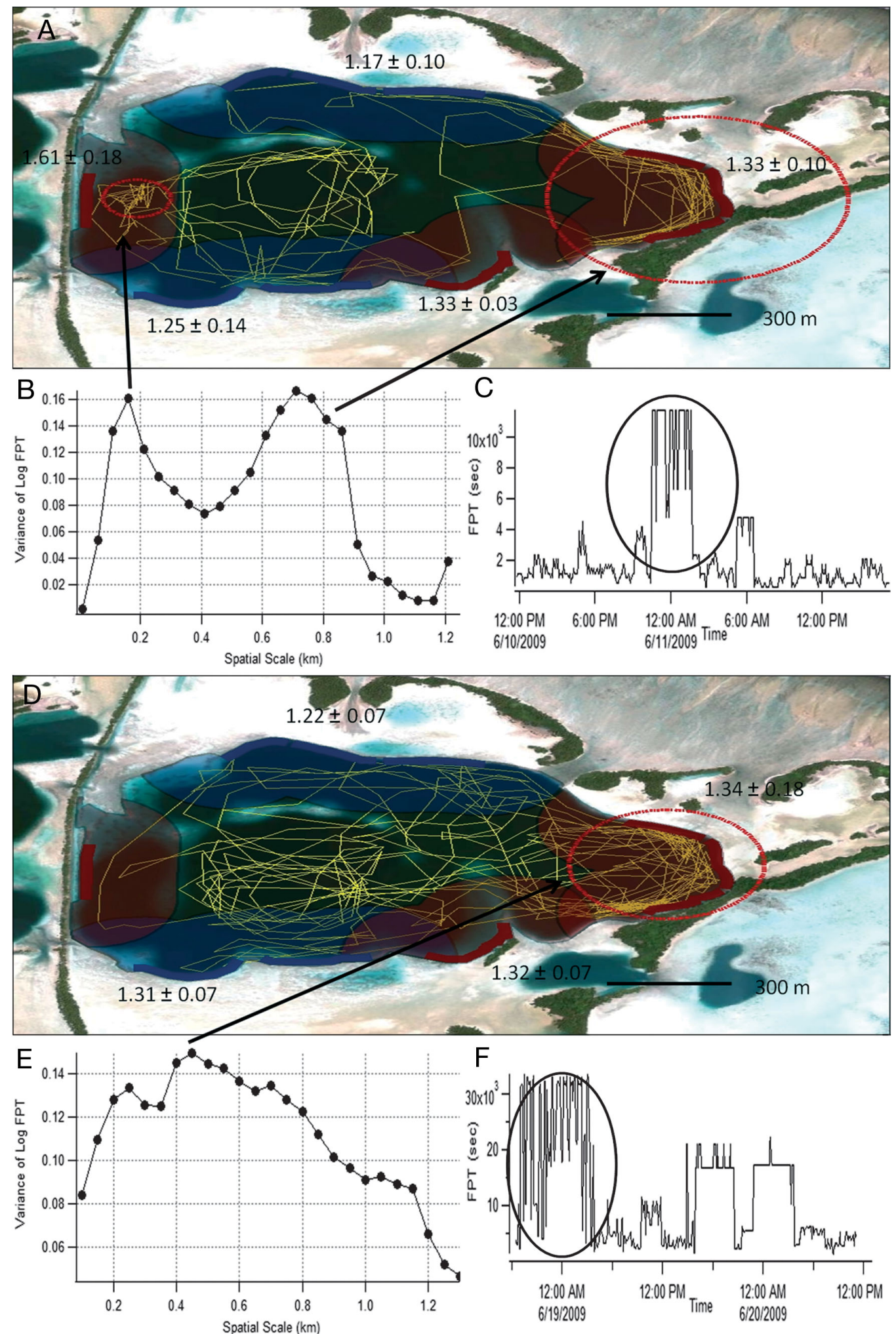

Fig. 6. Manta alfredi. Location of area-restricted searching (ARS; red circles) as determined by first passage time (FPT) for (A) Manta 1 and (D) Manta 2. (B,E) ARS was calculated from the peak in log variance FPT (scale of ARS), and (C,F) the time and date of maximum FPT. The changes in fractal values of movements along different ledges are also given (A,D). Relative differences in plankton biomass along ledges are denoted by red (high biomass) and blue (low biomass) 


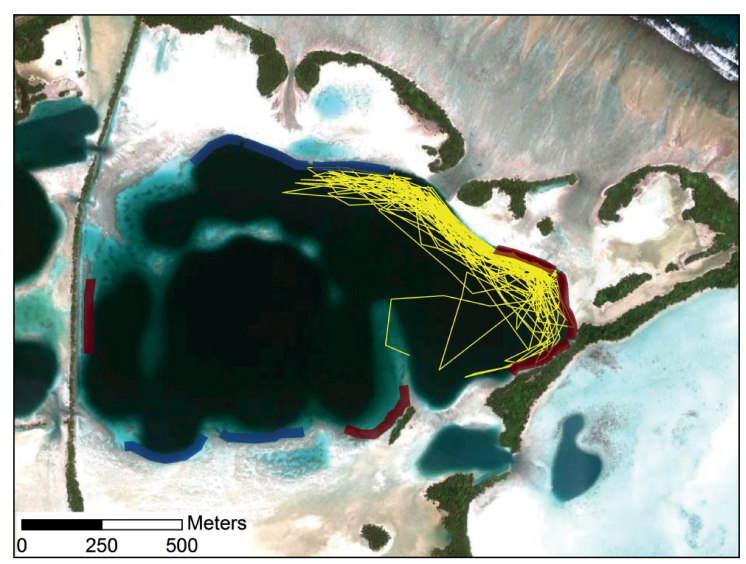

Manta 3

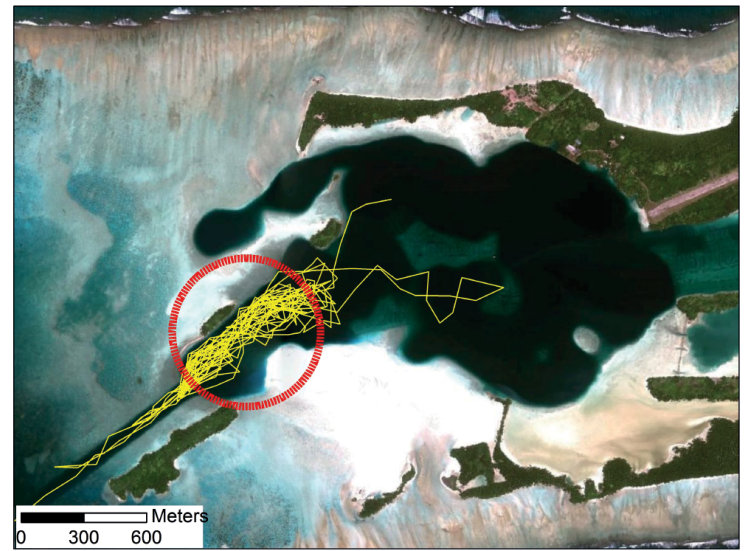

Manta 6

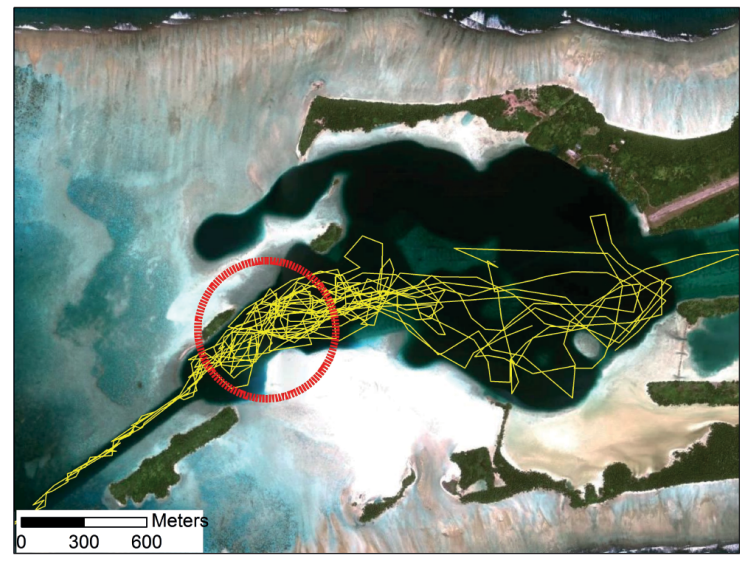

Manta 8

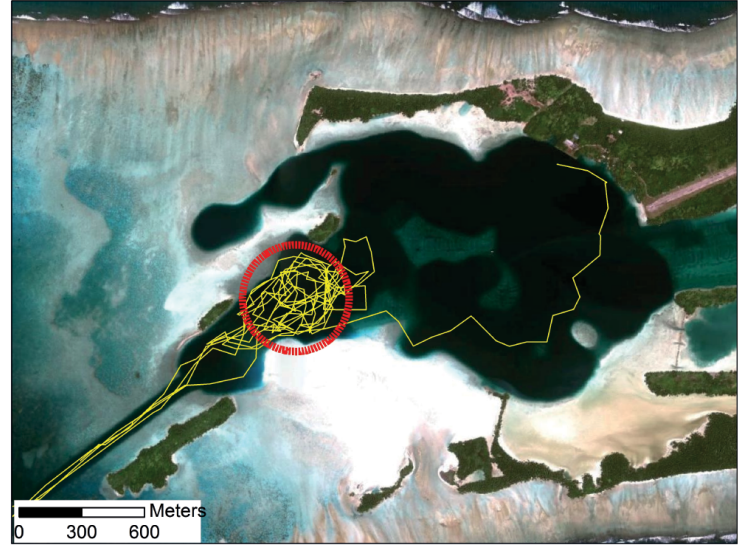

Manta 5

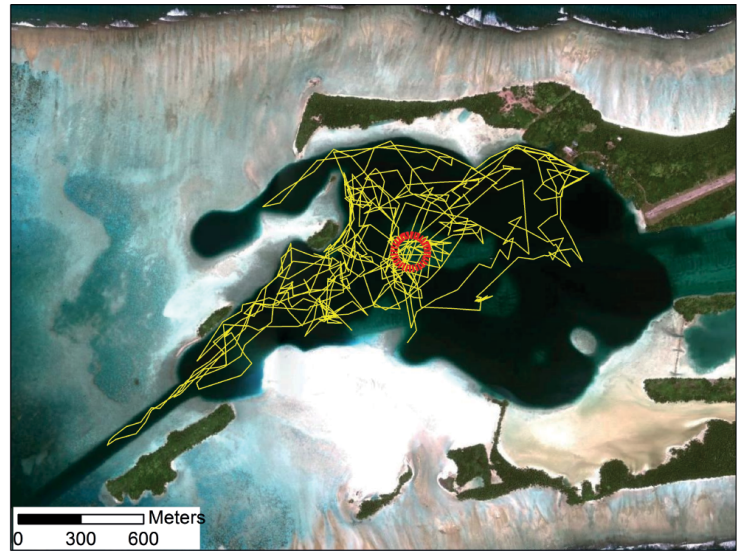

Manta 7

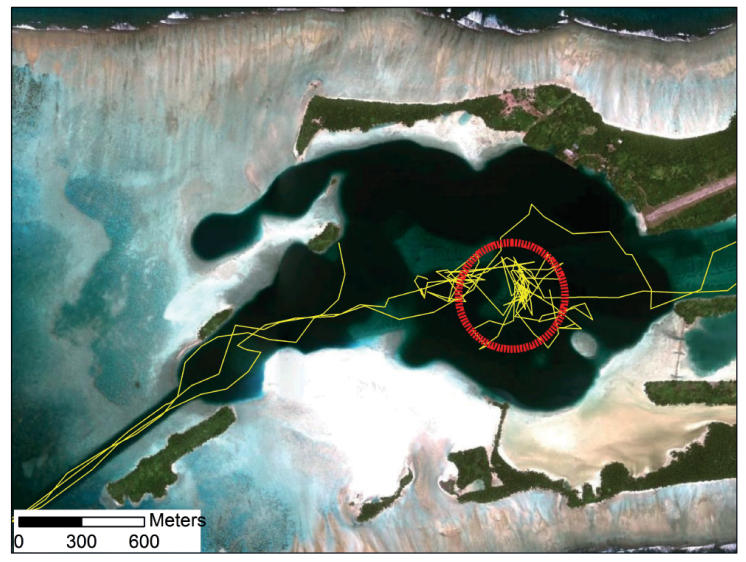

Manta 10

Fig. 7. Manta alfredi. Location of area-restricted searching (ARS, circles) for individual mantas, as determined by first passage time (FPT). All mantas were tracked in the west lagoon, with the exception of Manta 3. Note the lack of ARS for Manta 3, but the movements were confined to a ledge with high plankton biomass (red marked ledge) or the continuous and adjacent ledge

ods (days). Most studies quantifying ARS have focused on large spatial scales that encompass the entire range of the animal being studied, where scale of searching is defined at $10 \mathrm{~s}$ to $100 \mathrm{~s}$ of kilometers (e.g. Fauchald \& Tveraa 2003, Bailey et al. 2009).
Understanding the structure of movements and animal responses to the environment is also important at much smaller scales (10s of meters, e.g. Sims \& Quayle 1998, Fritz et al. 2003, Bailey \& Thompson 2006). Although animals will respond to their envi- 
ronment over large scales, ultimately feeding and an important suite of other ecological actions occur at these smaller, more neglected spatial scales.

Manta rays swimming throughout the lagoons of Palmyra Atoll appear to utilize a domain at a spatial scale of $330 \mathrm{~m}$. The gradual increase in fractal $D$ at scales of 10 to $330 \mathrm{~m}$ is indicative of a CRW at those smaller scales (Doerr \& Doerr 2004, Nams 2005). This behavior does not appear at larger spatial scales, as movements are scale invariant $>330 \mathrm{~m}$. Furthermore, movements are straighter at the smaller scales than they are at the larger scale. The evidence for this interpretation is strengthened by the CRW analysis, which also suggests that CRWs are only performed at smaller spatial scales. When we combine these results with the spatial scale of heterogeneous movements (patch use at 300 to $500 \mathrm{~m}$ ), we can conclude that manta rays may use a CRW to move between or locate plankton patches, but at larger scales they demonstrate home-ranging behavior. These results may also suggest that patch size is large relative to the inter-patch distance. These results are consistent with others showing that elasmobranchs demonstrate scale-dependent behavior at least when tracked for short periods of time (Papastamatiou et al. 2009, 2011, Levin et al. 2012). Blacktip reef sharks Carcharhinus melanopterus at Palmyra also appear to use a random walk to move between patches, but at smaller spatial scales they may use a directed walk to head towards specific locations (Papastamatiou et al. 2009). Sixgill sharks Hexanchus griseus move using a CRW at small spatial scales but deviate from model predictions over a longer diel cycle by demonstrating home-rangeing behavior (Levin et al. 2012). A mechanistic model suggested that an animal moving with a biased CRW (where it consistently turns in a certain direction) will maintain a home range if the animal possesses a 2-part memory system: a reference (i.e. it remembers that high-quality patches are in the area) and a working memory (i.e. it avoids visiting patches that were recently utilized, Van Moorter et al. 2009). Such a model can explain how randomly moving animals can still maintain a home range.

Within the various forms of CRWs, computer simulations predict that straighter (i.e. more correlated) random walks are more effective at locating resources than more tortuous searches (Zollner \& Lima 1999). Manta movements at the smaller spatial scales $(<330 \mathrm{~m})$ were straighter than at larger scales suggesting that straighter CRWs may be performed to move between patches, although the CRWs are still somewhat tortuous. Computer simulations predict that the differences in effectiveness between straighter and tortuous random walks decline as resource abundance increases, so observed patterns of movement may reflect relatively high abundance of resources within the lagoons (Zollner \& Lima 1999). Manta rays show selection for deeper lagoon microhabitats in the west lagoon, but select ledges within the east lagoon (P. A. DeSalle et al. unpubl.). Overall, manta ray activity spaces are broader and less elongated than those of blacktip reef sharks tracked in the lagoons (Papastamatiou et al. 2009). These differences in movement geometry, activity space shape, and habitat selection are likely driven by the very different foraging strategies (piscivore versus planktivore) of these elasmobranchs.

Our movement analysis only focuses on 1 relatively confined spatial scale (atoll lagoons), and cannot be extrapolated towards movements at much larger scales (e.g. when mantas leave the atoll). For example, whale sharks also make localized movements within coastal regions for weeks, before making seasonal (and likely directed) migrations which can involve swimming $1000 \mathrm{~s}$ of $\mathrm{km}$ (e.g. Wilson et al. 2006). At large spatial scales, planktivorous basking sharks are more efficient at locating broad prey patches than predicted by a simple random walk, and it was suggested that they may use horizontal Lévy flights, although the coarse resolution of satellite tracking prevented empirical testing of this hypothesis (Sims et al. 2006). Further investigation will also be required to determine whether and why manta movements may differ in other focal nonlagoon habitats (e.g. open ocean environment, Clark 2010). In addition, the physical structure of the lagoons will also limit the search patterns of manta rays. For example, long-distance movements are more unlikely due to the boundary conditions of the lagoons. However, the spatial domain identified by our analysis (at $330 \mathrm{~m}$ ) is still considerably smaller than the scale of the lagoons ( 1 to $2 \mathrm{~km}$ ), indicating that this domain is genuine and not an artificial consequence of lagoon shape.

In accordance with our predictions, when manta rays encountered areas with high plankton densities (specific coral ledges), they demonstrated ARS behavior. This behavior was particularly apparent at ledges adjacent to habitat with native Pisonia trees (McCauley et al. 2012). When encountering highquality foraging areas, mantas demonstrated typical ARS behavior with more tortuous movements, and frequent changes in direction, which enabled them to remain within a localized area (Benhamou 1992, Fauchald \& Tveraa 2003). Although it may appear 
logical for predators to display ARS behavior when locating prey, an increasing number of studies are showing that ARS may not always increase feeding success (e.g. Robinson et al. 2007, Weimerskirch et al. 2007, Bestley et al. 2010). This is likely the case where prey are widely dispersed, and capturing 1 individual does not necessarily mean there are other individuals close by. However, plankton are often distributed in more defined clumps, even at the spatial scale of meters (e.g. Owen 1989), hence ARS behavior should lead to increased foraging rates (Sims \& Quayle 1998). Furthermore, filtering rates and even prey selection (small versus large plankton) are going to be closely linked to the filter feeders' swimming speed (Paig-Tran et al. 2011). For the mantas tracked in areas where plankton measurements were also taken, movement tortuosity increased with increasing plankton concentration, reaching a plateau at approximately 0.1 to $0.2 \mathrm{~g} \mathrm{~m}^{-3}$. In addition, manta rays increased their residence time in high-density patches by a magnitude of 6.5. This suggests that increased tortuosity at plankton biomasses $>0.1$ to $0.2 \mathrm{~g} \mathrm{~m}^{-3}$ does not increase foraging rates, although this interpretation should be treated with caution as it is based on a small sample size. Basking sharks also increased residence times within patches as plankton concentration increased, with a minimum threshold of 0.48 to $0.7 \mathrm{~g} \mathrm{~m}^{-3}$ (Sims \& Quayle 1998, Sims 1999). Basking sharks did not respond to plankton patches $<0.48 \mathrm{~g} \mathrm{~m}^{-3}$, suggesting that they have a higher feeding threshold. The higher threshold for basking sharks may be related to differences in size, swim speeds, and gill-raker morphology (Sims 1999, Paig-Tran et al. 2011). While there are locations with predictably higher abundance of plankton (particular ledges), patches are likely to be found throughout the lagoons, and feeding has been observed at more central lagoon locations. Due to logistical issues, we were not able to sample plankton in the west lagoon, and as such the function of ARS is less conclusive. We hypothesize that the location of ARS within the channel in the west lagoon is an area of high water flow, potentially increasing filter-feeding rates, with minimal search costs. Without measurements of flow rates, this hypothesis cannot be verified.

Previous studies have found that the agreement between results of FPT and fractal analysis can be species specific (e.g. Robinson et al. 2007). There was good agreement between the 2 techniques for manta rays, probably because ARS consists of both slowingdown movements and frequently turning. Technically, these 2 techniques are not measuring the same thing, as one measures time within a circle, while the other measures the length of the movement path over which patch use occurred (Robinson et al. 2007). At large scales, this may be particularly problematic, but perhaps not as much an issue at smaller scales (as in the present study), as the shape of ARS is likely to be circular (Robinson et al. 2007). Of course, in all cases of indirectly inferring feeding from horizontal movements, a caveat is that we assume that tortuosity and ARS behavior are directly related to foraging. These assumptions may be more valid for large mobile planktivores, but clearly animals do not forage continuously. It is difficult to identify simple resting periods in obligate continuous swimmers, such as manta rays, so at present we cannot separate potential 'resting' behavior from the observed times of foraging. Furthermore, some patch use may also be related to other behavioral actions such as visitation of cleaning stations, where smaller fishes remove parasites and other irritants from the manta's dermal surface, or aggregation for social or reproductive purposes.

Movement models are critical for predicting how fish will respond to changes in abiotic and biotic conditions, as well as anthropogenic impacts such as climate change, fishing, and habitat modification (e.g. Moffitt et al. 2009). They also have more general conservation implications, as they show how variation in habitat over small spatial scales can have a large effect on manta behavior and movements. The locations of ARS behavior suggest that important habitat includes channels and coral ledges with high abundance of plankton, which may lead to aggregations of individuals (as is the case on the high plankton biomass ledges of the east lagoon). For animals which move over large areas, protecting key habitats may be more feasible from a management standpoint than trying to protect all habitats within the entire home range. An understanding of movement dynamics and how mantas respond to prey also allows predictions as to how individuals may respond to changes or alterations in habitat. Urbanization and runoff may lead to eutrophication and enhanced plankton biomass in certain areas, which will likely affect how manta rays select habitats and patterns of movement. The life history characteristics of Manta alfredi make them particularly susceptible to overfishing, and they are currently listed as Vulnerable on the IUCN's threatened species list. It becomes all the more critical that quantitative studies of movements are used to more accurately evaluate essential fish habitat and to ultimately predict patterns of dispersal. 
Acknowledgements. We thank H. Young, A. Briggs, C. Burniske, M. DeGraff, E. Hoffman, T. Jen, N. Wenner, and E. Wulczyn for help with tracking. V. Nams read an earlier version of this manuscript and provided helpful input. Funding was provided by the National Science Foundation, Stanford Vice Provost for Undergraduate Education, and Woods Institute of the Environment. We also thank the staff of The Nature Conservancy and US Fish and Wildlife Service. Vemco Telemetry kindly lent us the use of some of their equipment. Finally, we thank the 4 anonymous reviewers whose comments greatly improved the manuscript. This manuscript represents PARC contribution 0083.

\section{LITERATURE CITED}

Bailey H, Thompson P (2006) Quantitative analysis of bottlenose dolphin movement patterns and their relationship with foraging. J Anim Ecol 75:456-465

Bailey H, Mate BR, Palacios DM, Irvine L, Bograd SJ, Costa DP (2009) Behavioural estimation of blue whale movements in the Northeast Pacific from state-space model analysis of satellite tracks. Endang Species Res 10: 93-106

Bartumeus F, Da Luz MGE, Viswanathan GM, Catalan J (2005) Animal search strategies: a quantitative random walk analysis. Ecology 86:3078-3087

Benhamou S (1992) Efficiency of area concentrated searching behavior in a continuous patchy environment. J Theor Biol 159:67-81

> Bestley S, Patterson TA, Hindell MA, Gunn JS (2010) Predicting feeding success in a migratory predator: integrating telemetry, environment, and modeling techniques. Ecology 91:2373-2384

Clark TB (2010) Abundance, home range, and movement patterns of manta rays (Manta alfredi, $M$. birostris) in Hawaii. PhD dissertation, University of Hawaii at Manoa, p 149

> Doerr VAJ, Doerr ED (2004) Fractal analysis can explain individual variation in dispersal search paths. Ecology 85:1428-1438

Fauchald P, Tveraa T (2003) Using first-passage time in the analysis of area-restricted search and habitat selection. Ecology 84:282-288

Fritz H, Said S, Weimerskirch H (2003) Scale-dependent hierarchical adjustments of movement patterns in a longrange foraging seabird. Proc R Soc Lond B Biol Sci 270: 1143-1148

Humphries NE, Queiroz N, Dyer JRM, Pade NG and others (2010) Environmental context explains Lévy and Brownian movement patterns of marine predators. Nature 465: 1066-1069

Kareiva PM, Shigesada N (1983) Analyzing insect movement as a correlated random walk. Oecologia 56: $234-238$

Levin PS, Horne P, Andrews KS, Williams G (2012) An empirical movement model for sixgill sharks in Puget Sound: combining observed and unobserved behavior. Current Biol 58: 1-22

McCauley DM, DeSalles PA, Young HS, Dunbar RB, Dirzo R, Mills MM, Micheli F (2012) From wing to wing: the persistence of long ecological interaction chains in lessdisturbed ecosystem. Sci Rep 2:409

Moffitt EA, Botsford LW, Kaplan DM, O'Farrell MR (2009)
Marine reserve networks for species that move within a home range. Ecol Appl 19:1835-1847

> Nams VO (1996) The VFractal: a new estimator for fractal dimension of animal movement paths. Landsc Ecol 11: 289-297

Nams VO (2005) Using animal movement paths to measure response to spatial scale. Oecologia 143:179-188

Nams VO (2006) Detecting oriented movement of animals. Anim Behav 72:1197-1203

> Nams VO, Bourgeois M (2004) Fractal analysis measures habitat use at different spatial scales: an example with American marten. Can J Zool 82:1738-1747

> Owen RW (1989) Microscale and finescale variations of small plankton in coastal and pelagic environments. J Mar Res 47:197-240

Paig-Tran EWM, Bizzarro JJ, Strother JA, Summers AP (2011) Bottles as models: predicting the effects of varying swimming speed and morphology on size selectivity and filtering efficiency in fishes. J Exp Biol 214:1643-1654

Papastamatiou YP, Lowe CG, Caselle JE, Friedlander AM (2009) Scale-dependent effects of habitat on movements and path structure of reef sharks at a predator dominated ecosystem. Ecology 90:996-1008

Papastamatiou YP, Cartamil DP, Lowe CG, Meyer CG, Wetherbee BM, Holland KN (2011) Scales of orientation, directed walks, and movement path structure in sharks. J Anim Ecol 80:864-874

Robinson PW, Tremblay Y, Crocker DE, Kappes MA and others (2007) A comparison of indirect measures of feeding behaviour based on ARGOS tracking data. Deep-Sea Res II 54:356-368

Sims DW (1999) Threshold foraging behavior of basking sharks on zooplankton: Life on an energetic knife-edge? Proc R Soc Lond B Biol Sci 266:1437-1443

Sims DW, Quayle VA (1998) Selective foraging behaviour of basking sharks on zooplankton in a small-scale front. Nature 393:460-464

Sims DW, Witt MJ, Richardson AJ, Southall EJ, Metcalfe JD (2006) Encounter success of free-ranging marine predator movements across a dynamic prey landscape. Proc R Soc Lond B Biol Sci 273:1195-1201

Turchin P (1996) Fractal analyses of animal movement: a critique. Ecology 77:2086-2090

Van Moorter B, Visscher D, Benhamou S, Borger L, Boyce MS, Gaillard J (2009) Memory keeps you at home: a mechanistic model for home range emergence. Oikos 118:641-652

> Viswanathan GM, Buldyrev SV, Havlin S, da Luz MGE, Raposo EP, Stanley HE (1999) Optimising the success of random searches. Nature 401:911-914

> Weimerskirch H, Pinaud D, Pawlowski F, Bost CA (2007) Does prey capture induce area restricted searching? A fine-scale study using GPS in a marine predator, the wandering albatross. Am Nat 170:734-743

> Wilson SG, Polovina JJ, Stewart BS, Meekan MG (2006) Movements of whale sharks (Rhincodon typus) tagged at Ningaloo reef, Western Australia. Mar Biol 148: 1157-1166

Young HS, McCauley DJ, Dunbar RB, Dirzo R (2010) Plants cause ecosystem nutrient depletion via the interruption of bird-derived spatial subsidies. Proc Natl Acad Sci USA 107:2072-2077

> Zollner PA, Lima SL (1999) Search strategies for landscape level inter-patch movements. Ecology 80:1019-1030 